\title{
Evaluation of shear force and fractography of friction stir spot welded joints of AA 6082-T6 alloy
}

\author{
Sudhir Kumar*, Sachin Jambhale**, Manish Maurya***, Sanjeev Kumar**** and \\ Saurabh Pandey* \\ * Department of Mechanical Engineering, Greater Noida Institute of Technology, Greater Noida, India \\ ** Department of Mechanical Engineering, Mahatma Gandhi Mission's College of Engineering and Technology, Noida, India \\ *** Department of Mechanical Engineering, Accurate Institute of Management and Technology, Greater Noida, India \\ **** Department of Mechanical Engineering, J.C. Bose University of Science \& Technology, YMCA, Faridabad, India \\ ***Corresponding Author: manishmaurya33@gmail.com
}

Submitted : 15/04/2020

Revised : $21 / 10 / 2020$

Accepted :31/10/2020

\begin{abstract}
This experimental work investigates the tensile behavior of friction stir spot welded joints from $3 \mathrm{~mm}$ thick aluminum alloy AA6082-T6 sheets. Taguchi $\mathrm{L}_{9}$ orthogonal array was used for process parameters, tool rotational speed (TRS), dwell time (DT), and shoulder diameter (SD), with consideration of three levels. Friction stir spot welding (FSSW) was performed on vertical milling machine. Tensile shear test was conducted on universal testing machine (UTM) to find out the tensile shear failure load (TSFL). The optimal combinations of parameters were at tool rotational speed of 2,000 rpm, dwell time of 15 seconds, and tool shoulder diameter of $16 \mathrm{~mm}$. Tool rotational speed had a substantial effect on tensile shear strength of FSSW joint. Scanning electron microscopy (SEM) tests revealed that the changes in microstructure in different zones of FSSW joint were observed. Tensile shear specimen was analyzed using SEM to observe the behavior of fracture surfaces. Significant ductility in the fracture surface was evident in the fractography. In this article, attention is focused on the influence of joining parameters on the mechanical behavior of the friction stir spot weld under the tensile shear load condition.
\end{abstract}

Keywords: Fractography; Friction stir spot welding (FSSW); Heat affected zone (HAZ); Scanning electron microscopy (SEM); Thermo-mechanically affected zone (TMAZ).

\section{INTRODUCTION}

Aluminum is a key enabler in helping auto and defence industry to meet the significantly rising fuel efficiency standards and emissions goals. Downweighting and downsizing of the vehicles were involved in early 1980s to encourage the economy of fuel and to maximize the efficiency. The downsizing of vehicles is associated with increased risk of fatal injury for occupants. Aluminium and its alloys have significant potential to decrease the weight of vehicle components. Higher strength to weight ratios, better fracture toughness, significantly increased life, economical reasons, performance, affordability, aesthetics, technological advancements, and government 
regulations are factors justifying the need for aluminium alloys in industries. Therefore, the challenge of establishing acceptable joining technologies for aluminium alloys is natural (Ghassemieh (2011), Fentahun and Savaş (2018), and Todor \& Kiss (2016)).

After the body panels are shaped into the desired shapes, joining the other parts of the automotive components is required. There are difficulties in sustaining the mechanical properties while welding heat treatable 6xxx series aluminium alloys with conventional fusion welding processes. Resistance spot welding (RSW) is a typical traditional fusion welding process. This process is used for welding steel sheets used in aircraft and automobile industries owing to its low capital cost and ease of maintenance. However, this welding technique can not be applied easily to aluminum alloys because of its physical properties like high conductivity, tendency to degrade the electrodes, surface oxide film, and low strength at elevated temperature. In modern years, significant efforts have been made to clarify weldabilites of various aluminium alloys using different variants of friction stir welding process. Friction stir spot welding (FSSW), a new solid-state welding technique, was prepared by Mazda Motor Corporation and Kawasaki Heavy Industries in 2003 for lap joining of aluminum sheets (2005). FSSW is a more energy-efficient process than conventional resistance spot welding and other allied processes. Porosity and distortion are the general defects found in RSW. FSSW joints are stronger than those of RSW and spot clinching. There are no effects of contaminants and oxides on the surface in FSSW process that generally occurs in RSW. Several defects related to melting and solidification during fusion welding are avoided in FSSW, remaining in solid state. The low heat generated between the tool and work piece due to stirring action will produce the sound weld between AA 6082-T6 alloy sheet (Effertz et al. (2016)).

\section{LITERATURE REVIEW}

Effertz et al. (2017) evaluated the influence of the process parameters like plunge depth, rotational speed on lap, plunge time, and shear force using Taguchi method. The results revealed that the plunge depth is the significant parameter for obtaining the best lap shear force. The spot welded joints prepared were good in strength with 11.3 KN highest TSFL. Bozzi et al. (2008) performed FFSW to evaluate the dwell time on the tensile shear strength microstructure of the weld. The shear strength increased with the increase in the dwell time. A long dwell time made a larger welded area, but at the same time, intermetallic compounds (mainly $\mathrm{FeAl}, \mathrm{Fe}_{2} \mathrm{Al}_{5}$, and $\mathrm{FeAl}_{2}$ ) with high micro hardness were formed. Ahmed et al. (2016) investigated micro-hardness, tensile shear behavior, fracture surfaces, and microstructure of friction stir spot welded high Mn TWIP steel. FSSW had affected the hardness. 13 $\mathrm{KN}$ of maximum tensile shear load was found at $750 \mathrm{rpm}$. Maximum extension was found for $4 \mathrm{~mm}$ at $500 \mathrm{rpm}$ in all the joints. Ductile dimpled fracture obtained in the fractured surface had approved the absence of embrittlement in welded joints. Mazzaferro et al. (2015) investigated the influence of TRS and dwell time on the microstructure and mechanical properties of lap-joints. At different welding zones, mechanical and chemical stabilization of the austenite was found. At lowest TRS and highest DT combination of welding parameters, the highest joint strength was observed. Elfar et al. (2016) investigated the effect of FSSW parameters, that is, rotational speed, transverse speed, and pin-off set-on tensile strength for aluminium and brass using L9 OA. ANOVA results concluded that traverse speed is the most significant factor, followed by pin offset. Tutar et al. (2017) studied RSW method for TWIP steel sheet, which was cold-rolled to $15 \%$ reduction in thickness. The welding parameters were optimized to maximize the peak tensile shear load. The indentation of the joints was minimized by Taguchi L9 orthogonal array.

Prasath et al. (2016) performed friction stir welding on dissimilar Magnesium alloy between AZ 31 and ZM 21. Taguchi method was used to design the experiment. The optimum levels of the rotational speed $2100 \mathrm{rpm}$, tool of square pin profile geometry, and axial force $4 \mathrm{KN}$ were found. Sameer and Birru Bayazid et al. (2020) investigated the metallurgical and mechanical properties of friction stir welded dissimilar joints of AZ91 and AA 6082 alloy. Bayazid et al. (2015) investigated the effect of welding parameters like rotational speed, travel speed, 
and plate's position on microstructural and mechanical characteristics of friction stir welded joint of $\mathrm{Al} 6063$ and $\mathrm{Al}$ 7075 alloys via Taguchi method. Maximum tensile strength was obtained at $1600 \mathrm{rpm}$ of tool speed, $120 \mathrm{~mm} / \mathrm{min}$ of travel speed. ANOVA analysis depicted that tool rotational speed, travel speed, and plates' position have 59, 30, and $7 \%$ impact on tensile strength of welded joint. Vignesh et al. (2016) investigated the strength of FSSW joints of Al alloy by fuzzy logic. Ozo et al. [15] and Hande [16] studied the weld effect on aluminum alloys and the effect of tool on FSSW. Beker [17], Haken et al. [18], Ahmet et al. [19], and Olatunji et al. [20] have investigated the influence of FSSW on aluminium alloys, and the effect of tool was also observed.

Various researchers working in this field have performed FSSW on different aluminum alloy. However, very few published articles are available on FSSW performed on AA 6082-T6 alloy sheets. Authors have made an attempt to observe the influence of TRS, DT, and SD on FFSW. The purpose of this novel work is to investigate the optimal parameters (TRS, DT, and SD) in FFSW of AA 6082 joints applying Taguchi technique. This work also aims to observe the effect of FSSW process parameters on microstructural details and fracture morphology of tensile shear specimens.

\section{EXPERIMENTAL SETUP}

\section{Material Selection}

In this study, aluminum alloy 6082 T6 was selected for FSSW. AA 6082 T6 is widely used in aircraft and automotive industries. AA 6082-T6 has highest strength in 6xxx series and had influenced the authors to select the material. Chemical composition and mechanical characteristics of AA 6082 T6 are given in Table 1 and Table 2.

Table 1. Chemical composition of AA6082-T6.

\begin{tabular}{|c|c|c|c|c|c|c|c|c|}
\hline Al & Si & Cu & Mg & Fe & Zn & Ti & Cr & Mn \\
\hline Balance & $0.69-1.20$ & 0.09 & $0.79-1.19$ & 0.49 & 0.24 & 0.14 & $0.39-0.34$ & 0.14 \\
\hline
\end{tabular}

Table 2. Mechanical Characteristics of AA6082-T6.

\begin{tabular}{|c|c|c|c|}
\hline Base Alloy & Ultimate Tensile Strength (MPa) & Yield strength (MPa) & \% Elongation \\
\hline AA 6082-T6 & 343 & 300 & 14.0 \\
\hline
\end{tabular}

\section{Tool Material Selection and Preparation}

In this research work, high speed steel (HSS) is used as tool material. It has higher red-hardness and wear resistance with enhanced toughness. The tools are presented in Figure 1. 


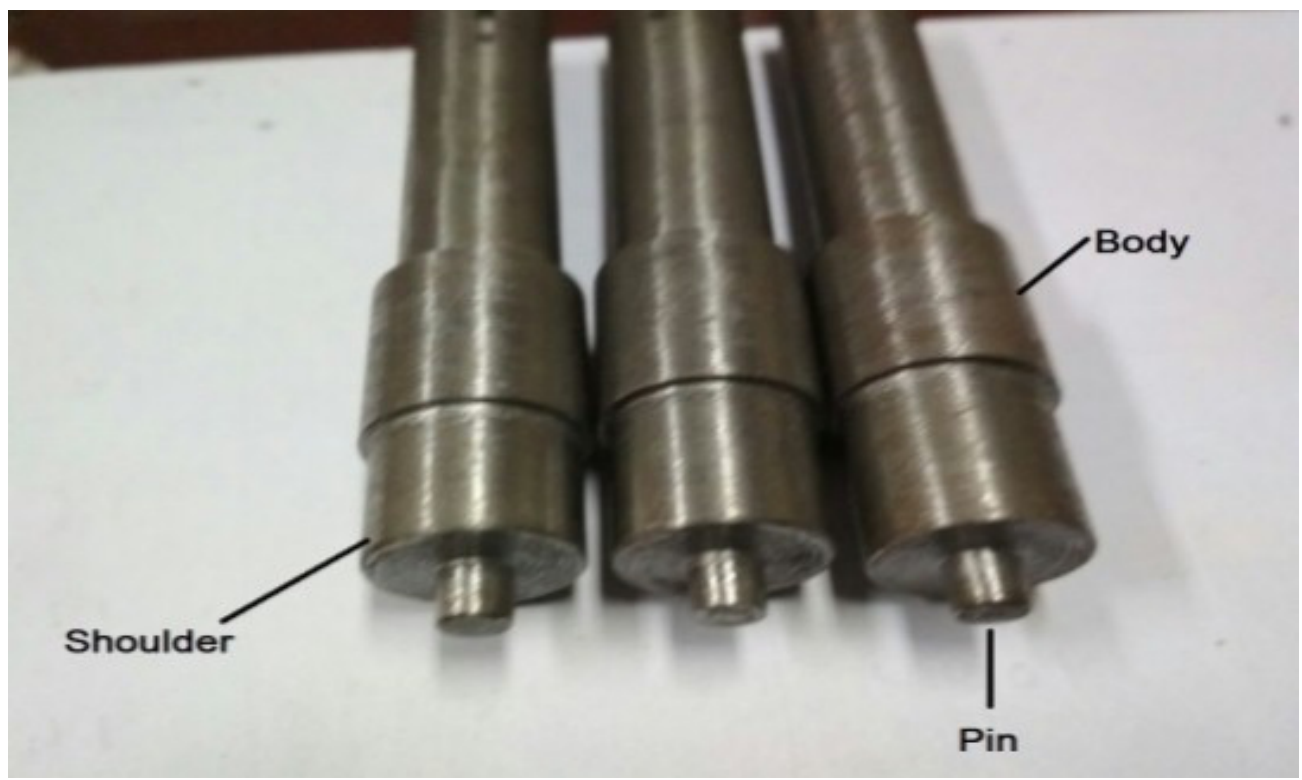

Figure 1. FSSW tools.

\section{SELECTION OF FSSW PROCESS PARAMETERS}

Mechanical properties of FSSW joints depend on the welding parameters like rotational speed, feed rate, plunge depth, pin diameter, shoulder diameter, and dwell time. These parameters are presented by cause and effect diagram in Figure 2. The tensile shear tests were conducted using lap shear specimens of FSSW AA6082-T6 aluminum alloy. Based on the literature survey and pilot experiments, three important process parameters along with their ranges are given in Table 3.

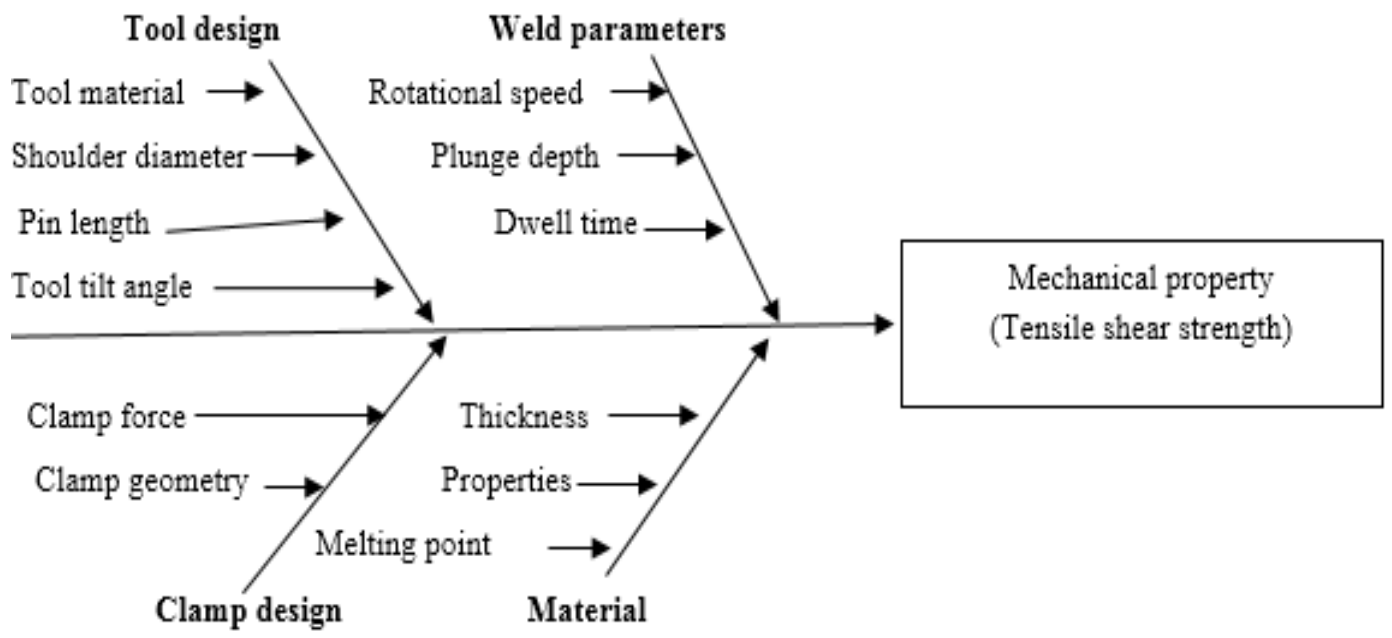

Figure 2. Cause and effect diagram (Ishikawa) of FSSW process. 
Table 3. Process parameters of their levels.

\begin{tabular}{|l|c|c|c|c|}
\hline & \multicolumn{4}{|c|}{ Level of factors } \\
\hline Parameters & Units & 1 & 2 & 3 \\
\hline Tool rotational speed (rpm) & RPM & 1000 & 1500 & 2000 \\
\hline Dwell time (Sec) & Sec & 5 & 10 & 15 \\
\hline Shoulder diameter (mm) & $\mathrm{mm}$ & 12 & 14 & 16 \\
\hline
\end{tabular}

\section{Taguchi Method Based Experiments}

Genichi Taguchi developed the statistical Taguchi method, which provides simple, systematic, and efficient approach for optimizing both manufacturing cost and overall performance. The purpose of this technique was to develop high quality products at minimum cost to the manufacturer. Taguchi principles have made widespread contributions to the industry by carrying focused awareness to noise, quality, and robustness.

\section{CONDUCTION OF FSSW EXPERIMENTS}

Experiments were carried out on vertical milling machine as shown in Figure 3. AA 6082 plates were rigidly fixed on the fixture. Heat produced due to friction between the rotating tool and the work piece had soften the material. Tool shoulder and pin geometry played a vital role during friction stir welding process (Sunnapu et al., 2020). The material becomes soft and tends to flow around the tool. This tends to greater friction and forms a welded joint. The tool was removed after the developed weld.

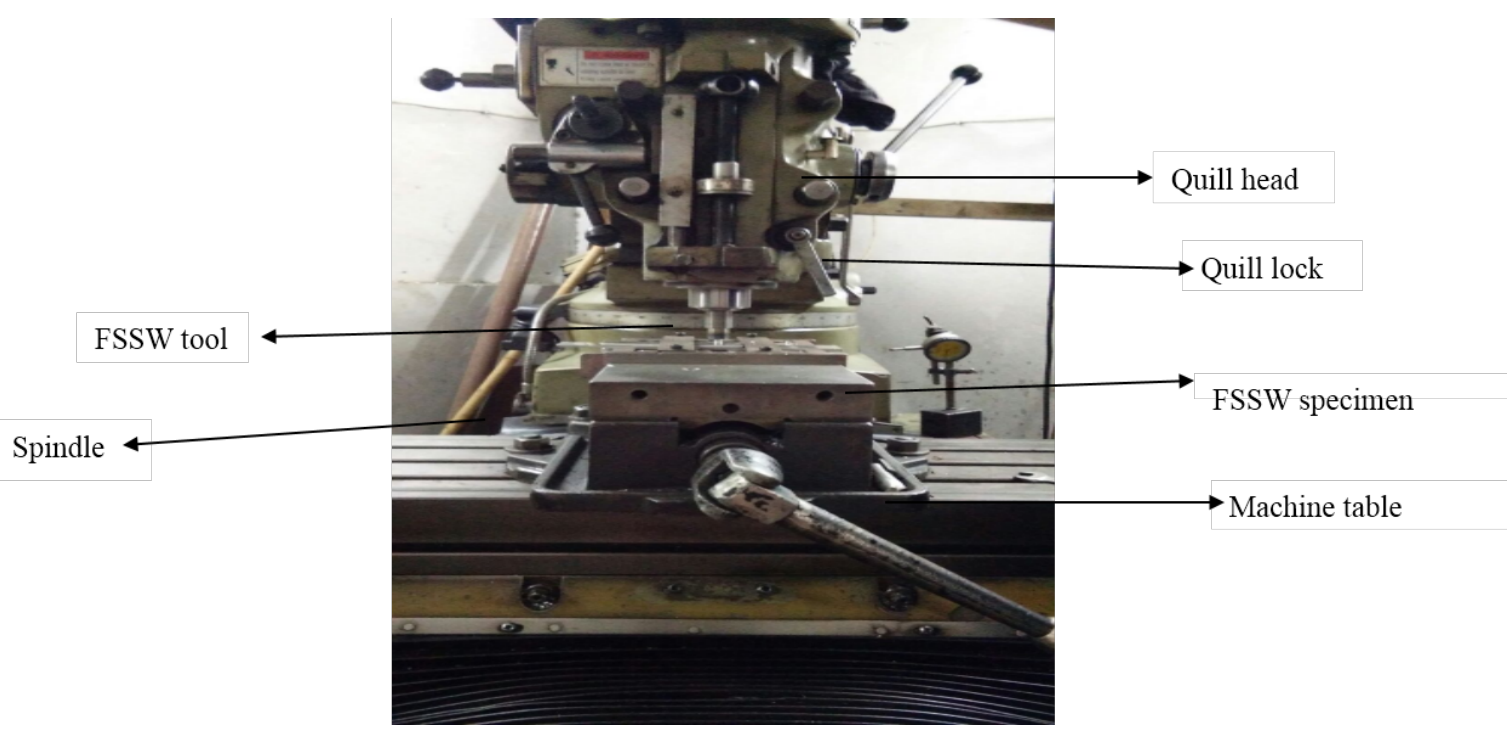

Figure 3. Experimental setup of FSSW. 


\section{Tensile Shear Test of FSSW Specimen}

Friction stir spot welded joints were used to perform tensile shear test. Dimensions of the specimen were $170 \mathrm{~mm}$ length, $30 \mathrm{~mm}$ width, and $3 \mathrm{~mm}$ thick. Tests were performed at room temperature with constant crosshead speed of $2 \mathrm{~mm} / \mathrm{min}$ with maximum load $100 \mathrm{KN}$ by computerized universal testing machine. Experiments were performed with three factors at three levels each, shown in Table 4. Table 4 illustrates the actual data of TSFL along with computed $\mathrm{S} / \mathrm{N}$ ratio value.

Table 4. Experimental results for TSFL and its calculated $\mathrm{S} / \mathrm{N}$ ratio.

\begin{tabular}{|c|c|c|c|c|c|}
\hline Sr. & $\begin{array}{c}\text { Tool rotational } \\
\text { speed (RPM) }\end{array}$ & Dwell time (Sec) & $\begin{array}{c}\text { Shoulder diameter } \\
(\mathrm{mm})\end{array}$ & TSFL (KN) & SNRA1 \\
\hline 1 & 1000 & 5 & 12 & 0.968 & -0.2824 \\
\hline 2 & 1000 & 10 & 14 & 1.329 & 2.4704 \\
\hline 3 & 1000 & 15 & 16 & 2.219 & 6.9231 \\
\hline 4 & 1500 & 5 & 14 & 1.688 & 4.5474 \\
\hline 5 & 1500 & 10 & 16 & 2.366 & 7.4802 \\
\hline 6 & 1500 & 15 & 12 & 2.351 & 7.4250 \\
\hline 7 & 2000 & 5 & 16 & 2.192 & 7.6834 \\
\hline 8 & 2000 & 10 & 14 & 2.418 & 7.6691 \\
\hline 9 & 2000 & 15 & & & \\
\hline
\end{tabular}

\section{MICROSTRUCTURAL ANALYSIS OF FSSW JOINT}

The soundness of welded joint was detected by the microstructure using scanning electron microscopy. Standard procedure was employed for preparation of samples to analyze SEM micrographs. A concentric Keller's reagent was used for etching the specimens. The micrographs of four main distinct microstructural zones, with the stir zone (SZ), thermo-mechanically affected zone (TMAZ), heat affected zone (HAZ), and base metal (BM) of the FSSW sample, were observed. The weld cross-sections of the FSSW joint (AA 6082-T6) are shown in Figure 4.

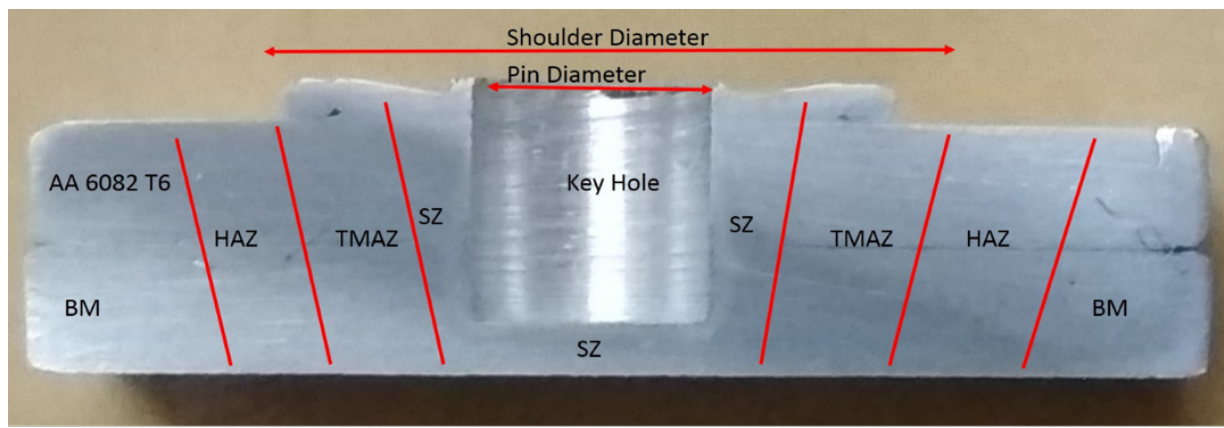

(a) 


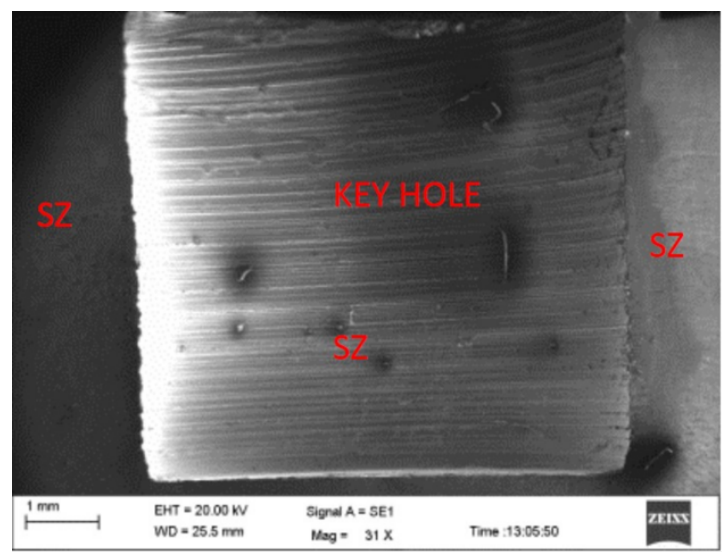

(b)

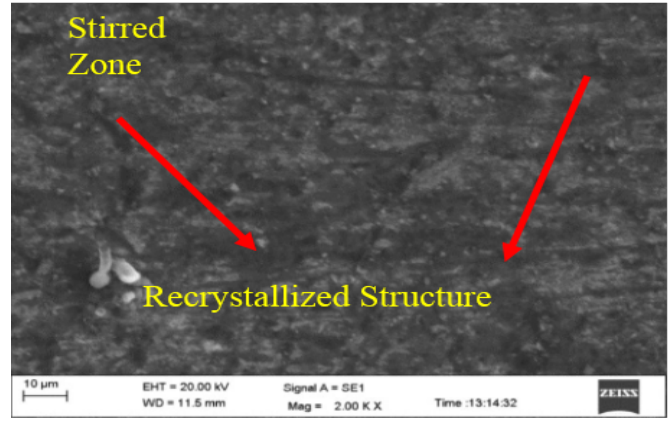

(c)

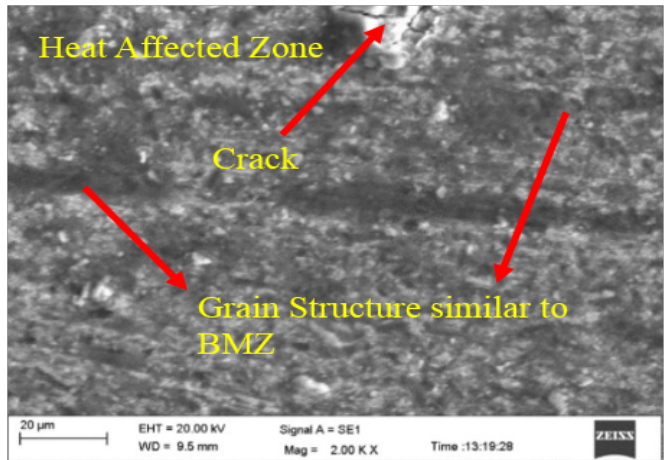

(e)

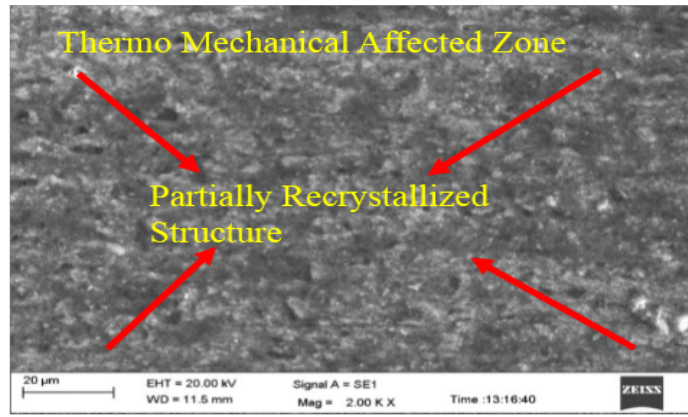

(d)

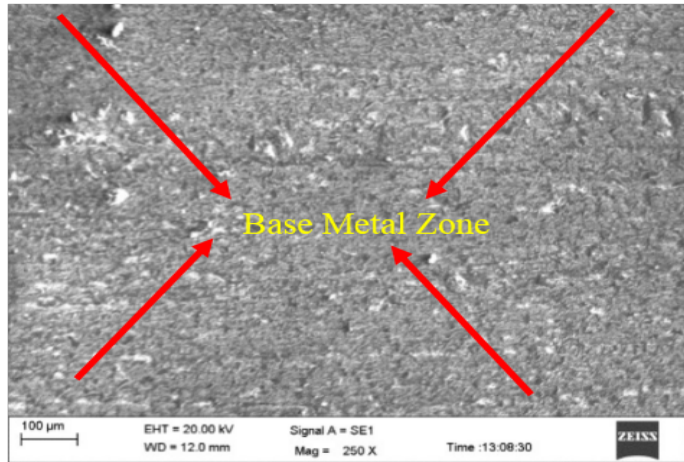

(f)

Figure 4. (a) Metallographic cross section showing FSSW zones; (b) key hole region near $\mathrm{SZ}$; (c) S Z; (d) TMAZ; (e) HAZ; (f) Base Metal SEM pictures of FSSW specimen No. 7 at welding condition of 2000 TRS, $5 \mathrm{sec}$ DT, and $16 \mathrm{~mm}$ zone.

Fig. 4 (a) shows different zones of FSSW sample. Magnified image of SZ is shown in Fig. 4 (b), illustrating the shape matching with the dimensions of tool. Fig. 4 (c) shows a dynamically recrystallized structure developed in the SZ due to higher TRS. This was due to higher compressive loads at elevated temperatures, which results in grain growth. Peak temperature of specimen reached during FSSW affects the phases generated in the final 
recrystallized grain structure. Cooling rate and composition of alloy had changed the phases. Partial recrystallization and modification were observed in Fig. 4 (d) due to the heat generated by friction and severe deformation at TMAZ. TMAZ includes all of the plastically deformed material within the joint region. Elongated grain structure was observed due to squeezing of material by tool. The grains are not recrystallized due to insufficient temperature in TMAZ (Muhayat et al., 2019). Partial bonding can be observed in Fig. 4 (e) at HAZ. More or less, the same properties as those of the BM were observed in HAZ with minor changes in strength and ductility. HAZ region can be heated suitably to induce some structural modifications, having no changes in the grain structure. Fig. 4 (f) shows BMZ, which remains unaffected during FSSW. FSSW produces more grain boundaries, with refined grain structure being thermodynamically susceptible to corrosion. Few traces of corrosion were seen in weld regions from SEM observation. Similar types of result were found by Prabhuraj et al. (2016). Absence of defects like cracks and porosity in the images had illustrated the quality welds.

\section{X-RAY DIFFRACTION (XRD) ANALYSIS}

The XRD analysis was conducted in PANalytical X'Pert Pro MPD under a working voltage of $45 \mathrm{kV}$ and 40 $\mathrm{mA}$ working current. Five points were considered for XRD from centre to $10 \mathrm{~mm}$ away from the centre of SZ. Residual stresses were measured for point 1 and point 2 in SZ and for point 3, point 4, and point 5 in TMAZ. The sin squared psi $(\sin 2(\psi))$ method is used for calculation of residual stresses to the depth of about $8 \mu \mathrm{m}$ in the aswelded specimen. Five different psi angles varying from $0^{\circ}$ to $45^{\circ}$ were utilized for analysis. The XRD analysis was done with scan parameters consisting of a $2 \theta$ range of $10^{\circ}$ to $90^{\circ}$, a $0.01^{\circ}$ increment, and a scanning rate of 0.020 /min using $\mathrm{Cu}-\mathrm{K} \alpha$ radiation $(\lambda=1.54 \AA$ ). Total measurement time of 15 minutes was utilized for five data points at different locations.

To identify the precipitated phase constitution of welded joint, the sample was cut from the weld region. In Figure 5, the XRD pattern shows that highest intensity peaks, namely, (111), (200), (220), (311), and (222), are distinctly visible in sample. Matching of XRD pdf standard had confirmed FCC aluminium phase with $\mathrm{h}, \mathrm{k}, 1$ value of 111 at peak with highest intensity. Table 5 shows the indexing of XRD pattern for AA 6082-T6 alloy welded sheet. Table 6 shows the indexing of XRD pattern for FSSW joint.

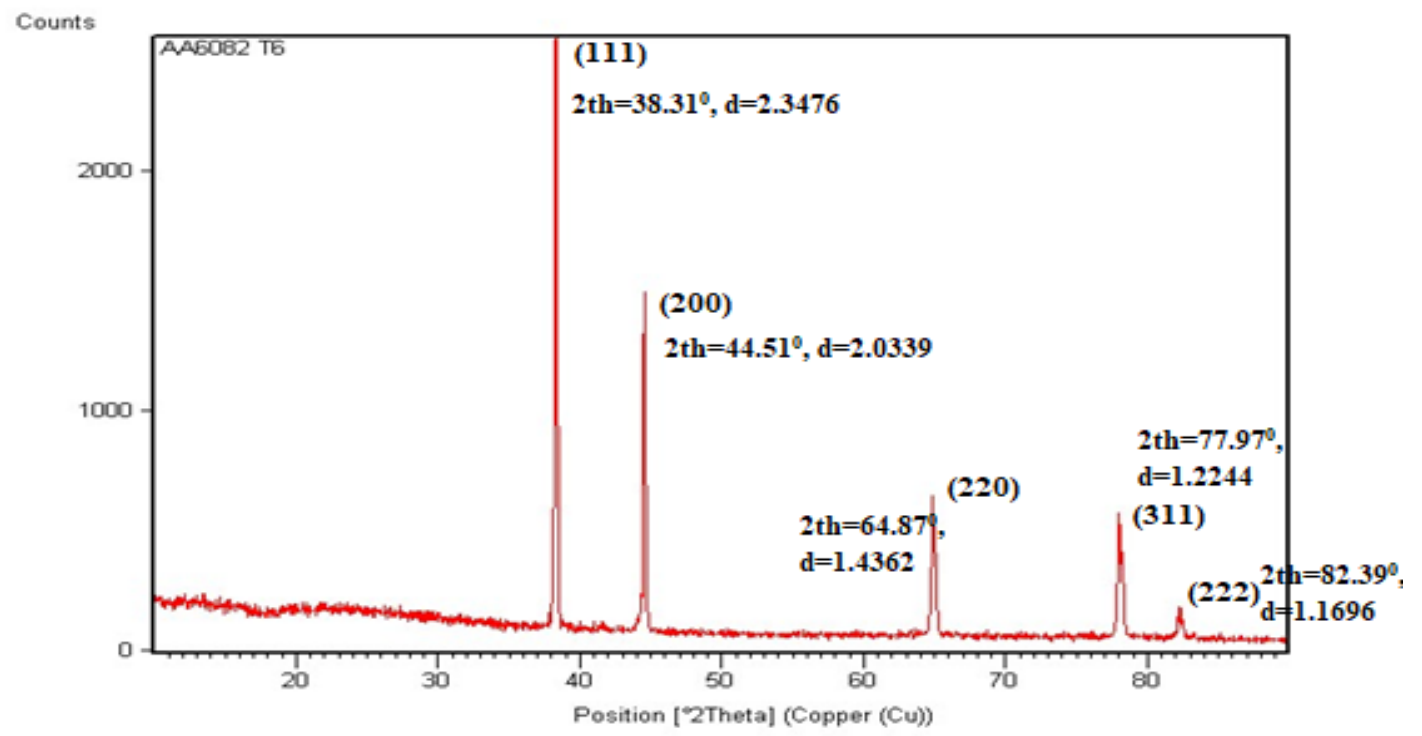

Figure 5. XRD pattern for fracture surfaces of AA6082 T6. 
Table 5. Indexing of XRD patterns.

\begin{tabular}{|c|c|c|c|c|}
\hline Sr & Peak No & $2 \theta$ & d spacing calculated in Excel & $\mathrm{h}, \mathrm{k}, 1$ \\
\hline 1 & 2569 & 38.31 & 2.3476 & 111 \\
\hline 2 & 1497 & 44.51 & 2.0339 & 200 \\
\hline 3 & 645 & 64.87 & 1.4362 & 220 \\
\hline 4 & 575 & 77.97 & 1.2244 & 311 \\
\hline 5 & 175 & 82.39 & 1.1696 & 222 \\
\hline
\end{tabular}

Table 6. Indexing of diffraction pattern and residual stresses for FSSW joint.

\begin{tabular}{|c|c|c|c|c|c|}
\hline No. & d spacing & $\operatorname{Sin} 2 \psi$ & $\mathrm{h}, \mathrm{k}, \mathrm{l}$ & Slope $(\mathrm{m})$ & Residual stress (MPa) \\
\hline 1 & 2.3476 & 0.0000 & 111 & -0.003 & -66.30 \\
\hline 2 & 2.0339 & 0.2960 & 200 & -0.003 & -76.52 \\
\hline 3 & 1.4362 & 0.8335 & 220 & -0.003 & -108.37 \\
\hline 4 & 1.2244 & 0.9762 & 311 & -0.003 & -127.11 \\
\hline 5 & 1.1696 & 0.5552 & 222 & -0.003 & -133.07 \\
\hline
\end{tabular}

X-rd analysis gives the details like d spacing, 2 theta, etc. Slope (m) can be found from the plot of $d$ spacing $\mathrm{v} / \mathrm{s} \sin ^{2} \Psi$ Fitzpatric et al. (2005). Residual stresses are calculated using equation 1 (2005).

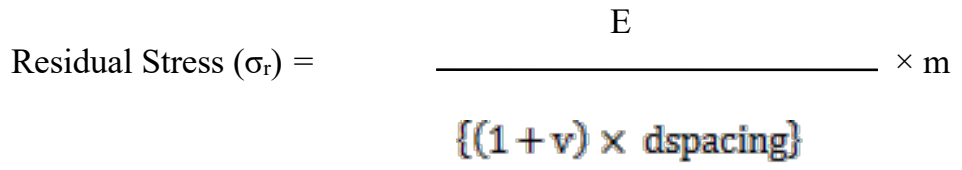

Where

$E$ (Young's Modulus) $=69 \mathrm{MPa}$.

$V($ Poisson's ratio $)=0.33$

$d$ spacing (Lattice spacing)

$m$ (Slope for plot of d spacing v/s $\left.\sin ^{2} \Psi\right)$.

The results of residual stress evaluated in the sample are shown in Table 6. Compressive residual stresses with negative values in the order of -66.30 to -133.07 were found. The compressive nature of stresses was found due to higher tool rotational speed. Residual stresses developed in welded zone had changed the lattice spacing. Due to compression in the material, the distance between crystallographic planes ( $\mathrm{d}$ spacing) decreases. Table 6 shows that a residual stress increases as the value of $d$ spacing decreases. Lesser value of compressive residual stresses at SZ region is due to reaction for compressive forces exerted by the tool shoulder. Also, the stirring action of the FSSW tool relieves some of the residual stresses in the SZ. Thermal expansion due to heat transferred from SZ leads to an increase in the value of compressive residual stresses at TMAZ (Jambhley et al., 2019). 


\section{ANALYSIS OF VARIANCE (ANOVA)}

Taguchi method along with ANOVA was employed at a 95\% confidence level for analyzing data using the $\mathrm{S} / \mathrm{N}$ ratio. The result of $\mathrm{S} / \mathrm{N}$ ratio analysis for the TSFL values is shown in Table 7 . The values in Table 7 indicate the correlation between reference sequence and obtained sequence. The bold values of $\mathrm{S} / \mathrm{N}$ ratios denote the significance of level affecting parameters for obtaining stronger joints. Optimal level of process parameters was depicted as $\mathrm{A}_{3} \mathrm{~B}_{3} \mathrm{C}_{3}$, that is, the TRS of 2,000 rpm, DT of $15 \mathrm{sec}$, and SD of $16 \mathrm{~mm}$. Rank 1 of TRS showed that TRS was the most significant parameter followed by DT and SD. Then, ANOVA, given in Table 8, includes DF (degree of freedom), S (sum of square), V (variance), F (variance ratio), and P (significant factor). Significant parameters and the selected optimal level indicate that the TRS plays a vital role in providing higher strength to FSSW joint. Heat generation due to proper mixing of material at higher TRS is responsible for strong joint. The influence of SD was less as compared to other parameters.

Table 7. Response table for Signal to Noise ratios.

\begin{tabular}{|c|c|c|c|}
\hline Level & Tool Rotation Speed (RPM) & Dwell Time (Sec) & Shoulder Diameter (mm) \\
\hline 1 & 3.037 & 3.983 & 4.653 \\
\hline 2 & 6.484 & 5.589 & 4.896 \\
\hline 3 & $\mathbf{7 . 3 9 0}$ & $\mathbf{7 . 3 3 9}$ & $\mathbf{7 . 3 6 2}$ \\
\hline Delta & 4.353 & 3.356 & 2.709 \\
\hline Rank & 1 & 2 & 3 \\
\hline
\end{tabular}

Table 8. ANOVA analysis of $\mathrm{S} / \mathrm{N}$ ratio for TSFL.

\begin{tabular}{|l|c|c|c|c|c|l|}
\hline Source & DF & Adj SS & Adj MS & F-Value & P-Value & \\
\hline Tool Rotation Speed & 2 & 1.14352 & 0.57176 & 42.37 & 0.023 & Significant \\
\hline Dwell Time & 2 & 0.61275 & 0.30638 & 22.70 & 0.042 & Significant \\
\hline Shoulder Diameter & 2 & 0.52389 & 0.26194 & 19.41 & 0.049 & Significant \\
\hline Error & 2 & 0.02699 & 0.01350 & & & \\
\hline Total & 8 & 2.30715 & & & & \\
\hline
\end{tabular}

\section{ESTIMATION OF OUTPUT CHARACTERISTICS}

Average values and main effects of TSFL are shown in Table 9. The optimal value of the TSFL was established on the particular levels of important process parameters. Substantial process parameters and their optimum levels have been selected as (3-3-3) (TRS $2000 \mathrm{rpm}$, DT $15 \mathrm{sec}$ and SD $16 \mathrm{~mm}$ ). The estimated mean of response characteristic can be calculated as $\mu \mathrm{TS}=\mathrm{TA}_{3}+\mathrm{TB}_{3}+\mathrm{TC}_{3}-2 \mathrm{~T}_{\mathrm{avg}}$

where $\mathrm{T}_{\mathrm{avg}}=$ overall mean $\mathrm{TSFL}=1.995 \mathrm{KN}$.

$\mathrm{TA}_{3}=\mathrm{TSFL}$ Average value at level 3 of factor TRS $=2.35 \mathrm{KN}$.

$\mathrm{TB}_{3}=\mathrm{TSFL}$ Average value at level 3 of factor $\mathrm{DT}=2.33 \mathrm{KN}$.

$\mathrm{TC}_{3}=\mathrm{TSFL}$ Average value at level 3 of factor $\mathrm{SD}=2.34 \mathrm{KN}$. 
Table 9. Average values and main effects of TSFL (raw data).

\begin{tabular}{|c|c|c|c|c|}
\hline \multirow{2}{*}{ Process parameter } & Level & $\begin{array}{c}\text { Tool rotational } \\
\text { speed }\end{array}$ & $\begin{array}{c}\text { Dwell } \\
\text { time }\end{array}$ & $\begin{array}{c}\text { Tool shoulder } \\
\text { diameter }\end{array}$ \\
\hline \multirow{2}{*}{$\begin{array}{c}\text { Average values (TSFL) } \\
\text { KN }\end{array}$} & L1 & 1.51 & 1.69 & 1.84 \\
\cline { 2 - 5 } & L2 & 2.14 & 1.96 & 1.82 \\
\cline { 2 - 5 } & L3 & 2.35 & 2.33 & 2.34 \\
\hline \multirow{2}{*}{ Main effects (TSFL) KN } & L2 - L1 & 0.63 & 0.27 & -0.02 \\
\cline { 2 - 5 } & L3 - L2 & 0.21 & 0.37 & 0.52 \\
\hline
\end{tabular}

Hence, $\mu_{\mathrm{TSFL}}=2.35+2.33+2.34-2 \times 1.995=3.04$.

The $95 \%$ confidence intervals of confirmation experiments $\left(\mathrm{CI}_{\mathrm{CE}}\right)$ can be measured by Equation (2) as follows:

$$
\left.\mathrm{CI}_{\mathrm{CE}}=\sqrt{F_{\alpha}\left(1, f_{\theta}\right) V_{\theta}\left[\frac{1}{\eta \boxminus f f}\right.}+\frac{1}{R}\right]
$$

where $\mathrm{F}(\alpha, 1, f \mathrm{e})=$ the $\mathrm{F}$ ratio at the confidence level of $(1-\alpha)$ against DOF 1 and error degree of freedom $f$ e. $\alpha$ is the confidance level. $\alpha$ is the level of risk, $\mathrm{Ve}$ is the error variance, and $f_{e}$ is the degrees of freedom for the error. By the value $\mathrm{Ve}=0.01350$ and $f_{e}=2$ in Table 15 , the confidence interval was measured. The total DOF is associated with the estimation of mean $\mu_{\mathrm{TF}}=2+2+2=6$ total number of experiments $(\mathrm{N})=3 \times 3=9$.

Effective number of replications ( $\left.\eta_{\text {eff }}\right)$ is measured using

$$
\eta \text { eff }=\frac{\mathrm{N}}{1+[\text { DOF associated in estimate of mean response }]}
$$

Thus, neff $=9 / 3=3$, and $\mathrm{R}=3$ is sample size for confirmation of the experiments

Tabulated $\mathrm{F}$ ratio at $95 \%$ confidence level, i.e., $\alpha=1-$ confidance limits $(95 \%)=0.5$

$\mathrm{F}_{\text {ratio }}(0.05,2)=18.91 \quad$ (From $\mathrm{F}$ tables)

$\mathrm{CI}_{\mathrm{CE}=+/-}\left[18.51 \times 0.01350[1 / 3+1 / 3]^{1 / 2}=+/ 0.41\right.$

The predicted optimal range is

$$
\begin{aligned}
& \left(\mu_{\mathrm{TSFL}}-\mathrm{CI}_{\mathrm{CE}}\right)<\mu_{\mathrm{TS}}<\left(\mu_{\mathrm{TSFL}}+\mathrm{CI}_{\mathrm{CE}}\right) \\
& 3.04-0.41<3.04<3.04+0.41 \\
& 2.63<3.04<3.45
\end{aligned}
$$




\section{CONFIRMATION TESTS}

The confirmation tests were performed by setting the process parameters at optimum levels. The TRS, DT, and SD were set at $2000 \mathrm{rpm}, 15 \mathrm{sec}$ and $16 \mathrm{~mm}$, respectively. The samples were subjected to tensile shear test. The value of the TSFL for FSSW joint of AA 6082-T6 was 3.2 KN at optimized process parameters. The reasons for this difference from the previously reported value in Table 4 of $2.422 \mathrm{KN}$ are due to different process parameters (2000 rpm, $5 \mathrm{sec}$, and $16 \mathrm{~mm}$ ).

Table 10. Predicted optimal values, confidence intervals.

\begin{tabular}{|c|c|c|c|}
\hline $\begin{array}{c}\text { Performance } \\
\text { measures/ } \\
\text { Responses }\end{array}$ & $\begin{array}{c}\text { Optimal set of } \\
\text { parameters }\end{array}$ & $\begin{array}{c}\text { Predicted } \\
\text { optimal } \\
\text { value }\end{array}$ & $\begin{array}{c}\text { Predicted confidence } \\
\text { intervals at 95\% confidence } \\
\text { level }\end{array}$ \\
\hline TSFL KN & $\begin{array}{c}(3-3-3)(2000 \mathrm{rpm}, 15 \mathrm{sec} \\
\text { and } 16 \mathrm{~mm})\end{array}$ & $3.04 \mathrm{KN}$ & $2.63 \mathrm{~N}<\mu_{\mathrm{TSFL}}<3.45$ \\
$\mathrm{KN}$
\end{tabular}

\section{INFLUENCE OF PROCESS PARAMETERS ON FSSW JOINT}

Figure 6 presents the influence of TRS on TSFL. Higher tool rotational speed resulted in more intense stirring and mixing due to large amount of heat generated. Frictional heat input, material flow, and the SZ area were intensified by the increased TRS. The load carrying capacity of the joint depends on the width of the joint. At higher TRS, the width of the joint increases, which provides more shear area to resist the external load. Hence, TSFL was directly proportional to the tensile strength of the weld. Welding at a lower rotational speed of $1000 \mathrm{rpm}$ had required more torque from the tool spindle. This was explained by the lack of plasticized material for welds produced at low rotational speed.

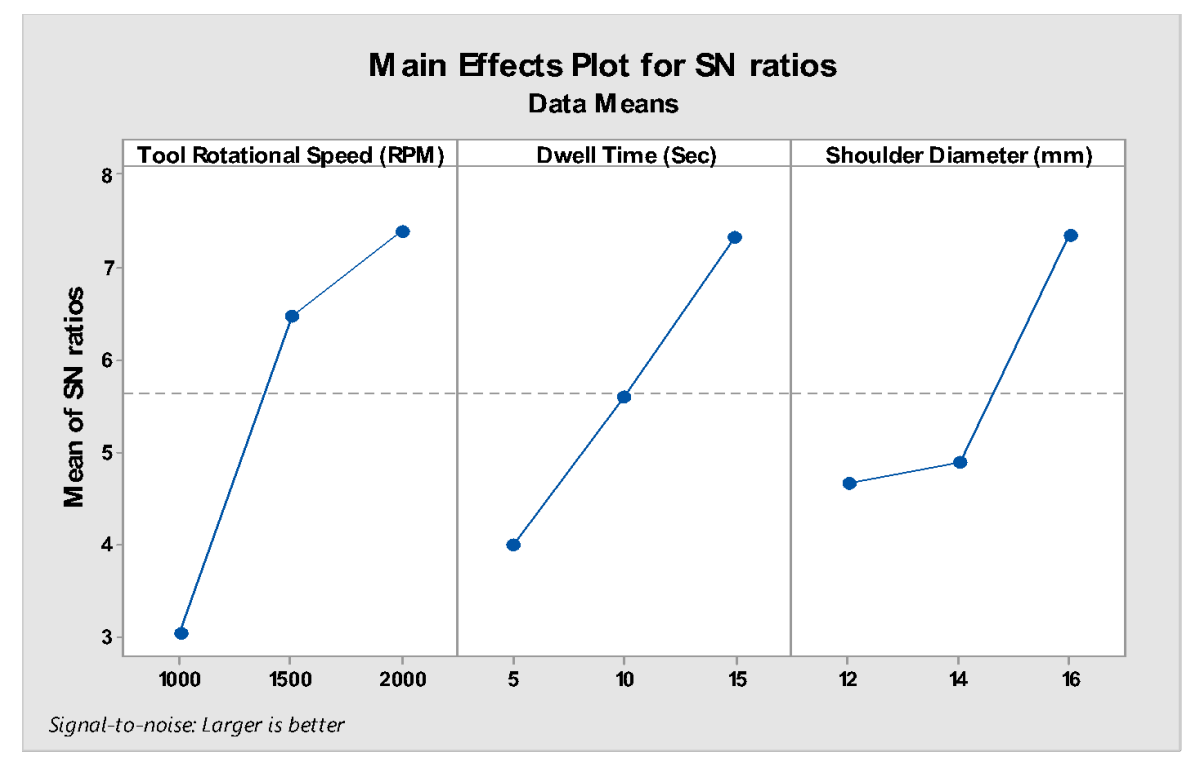

Figure 6. Main Effects Plot for SN ratios 
DT and heat input were closely correlated in FSSW process. Figure 6 illustrates the influence of DT on TSFL. A lack of heat input leads to problems concerning refilling the keyhole. At longer DT, softened HAZ becomes wider, and the bonding area was increased. The work piece was exposed to a higher elevated temperature for a longer time. A long DT was impractical for industrial applications since it may cause formation of inter-metallic layers. An excessive heat input will excessively soften the weld or cause the material to melt. In spite of drawbacks, longer DT is preferred to achieve stronger bonds. For achieving higher productivity, a combination of higher TRS and DT was required within the short span. The results showed a positive and significant influence of the dwell time. Figure 6 shows the effect of SD on TSFL. SZ area was increased as the tool shoulder diameter was enlarged. The sizes of microstructural zones were influenced by SD. The state of low temperature deformation had changed to high temperature deformation as the SD increases. Larger joint area due to larger SD increases the load bearing capacity of joint during lap shear test. Thus, increased fracture load had produced joint with higher strength. Heating and softening of material under the shoulder surface at higher SD may result in heat loss, when FSSW was carried out at higher TRS and DT.

Fig. 7 (a) shows contour plot for variation of TSFL with the two parameters dwell time and tool rotational speed. The variation of TSFL indicates darker green surface having maximum TSFL. There is a decrease in the TSFL value from dark green to light green surface below TRS of $1900 \mathrm{rpm}$ and below DT of 15 seconds. At TRS of 1,900 to 2,000 rpm and DT more than 15 seconds, the TSFL has the maximum value. Fig. 7 (b) shows the contour plot for variation of TSFL with the two parameters shoulder diameter and tool rotational speed. At TRS of 1,300 to $1,950 \mathrm{rpm}$ and SD more than $16 \mathrm{~mm}$, the TSFL will achieve the maximum value.

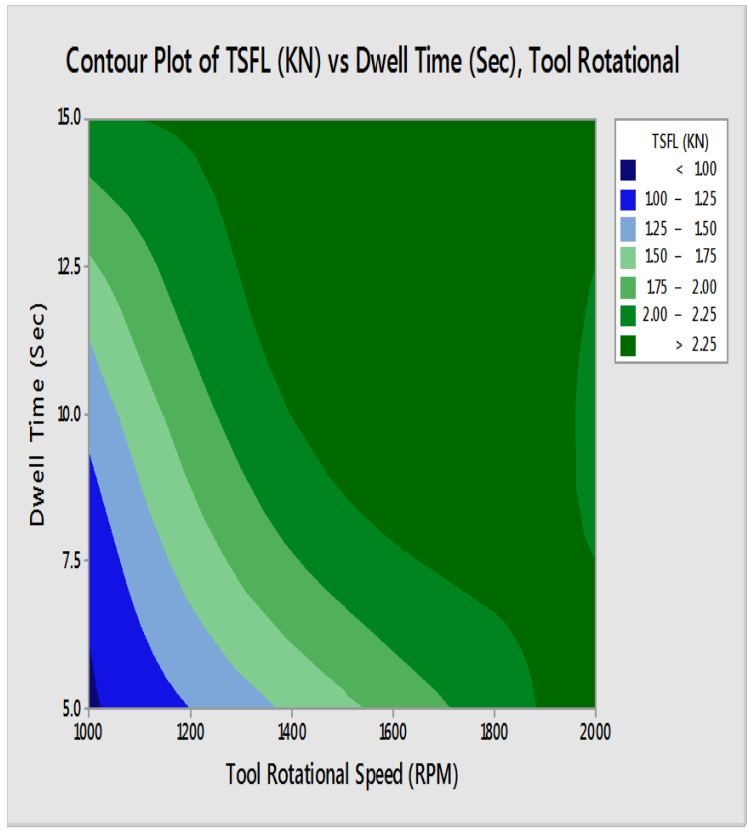

(a)

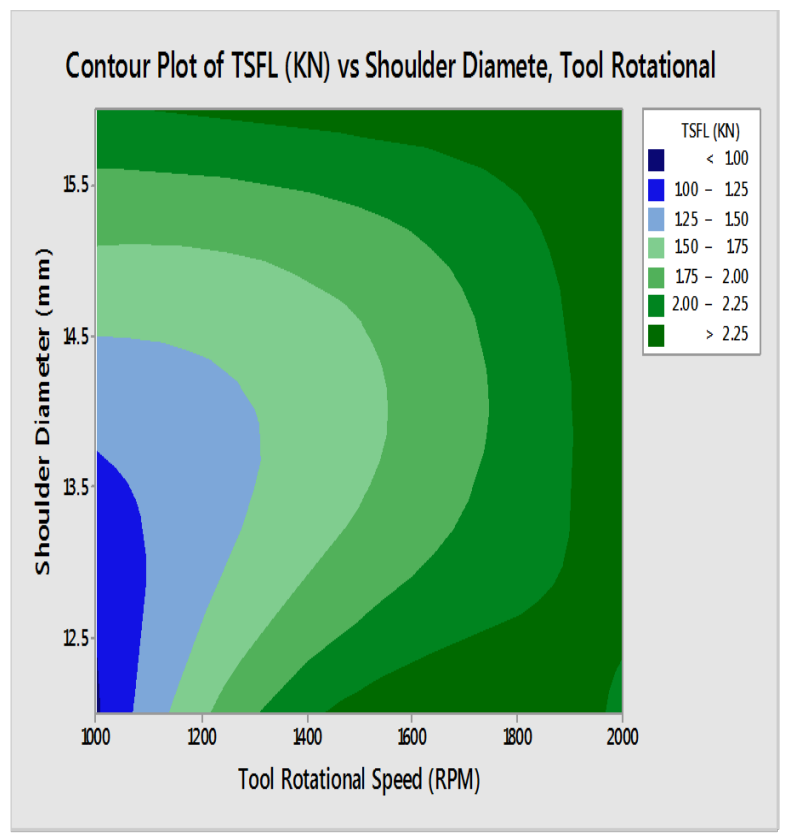

(b)

Figure 7. Contour plots: a) TSFL v/s DT and TRS; b) TSFL v/s SD and TRS. 


\section{MORPHOLOGY OF FRACTURE IN FSSW JOINT}

SEM images of different regions in the vicinity of cracks at the fracture surface were considered to characterize the tensile behavior of FSSW joint. Three specimens were considered for study. The images of sample no. 7 at 3 points $\mathrm{A}, \mathrm{B}$, and $\mathrm{C}$ with higher magnification of upper sheet and lower sheet of the weld are shown in Figures 8 and 9. Various spherical dimples were observed in the fracture mechanism as shown in Fig. 8 (b). The rupture of dimples was the indication of fracture occurred with degree of ductility at point A of top sheet. This ductility behaviour leads to the higher tensile strength of joint. Fig. 8 (c) shows that elongated dimples at point B indicate sound welding joint leads to higher tensile strength of the joint. Fig. 8 (d) illustrated the cleavege fascets seperated by risers. Tongues are also observed on the fascets. Cleavage microcracks were observed at the fascets. Fig. 9 (b) shows the fractograph charecterised by fan shaped patterns. This indicates the step by step propogation of cracks during tensile testing. Fig. 9 (c and d) depicts the fracture surfaces with brittle appearance indicating weaker bonding at points $\mathrm{B}$ and $\mathrm{C}$, respectively.

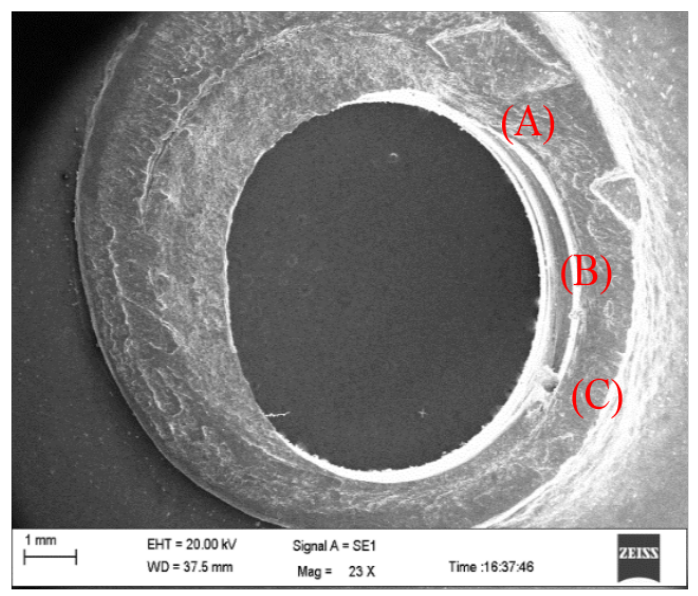

(a)

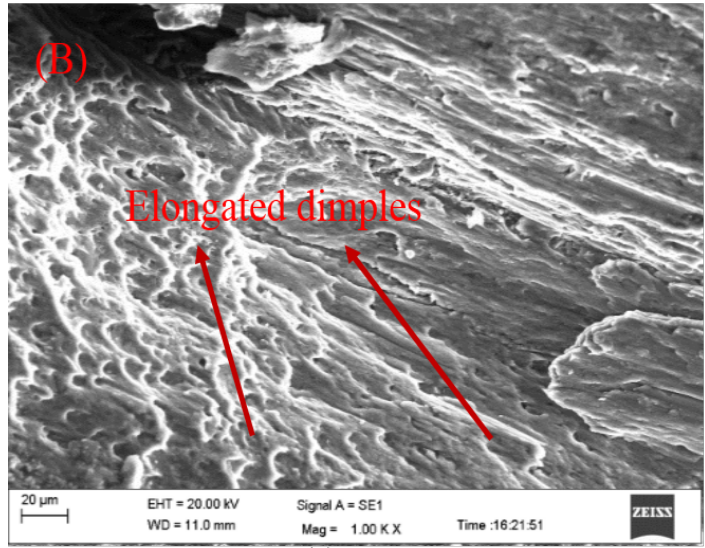

(c)

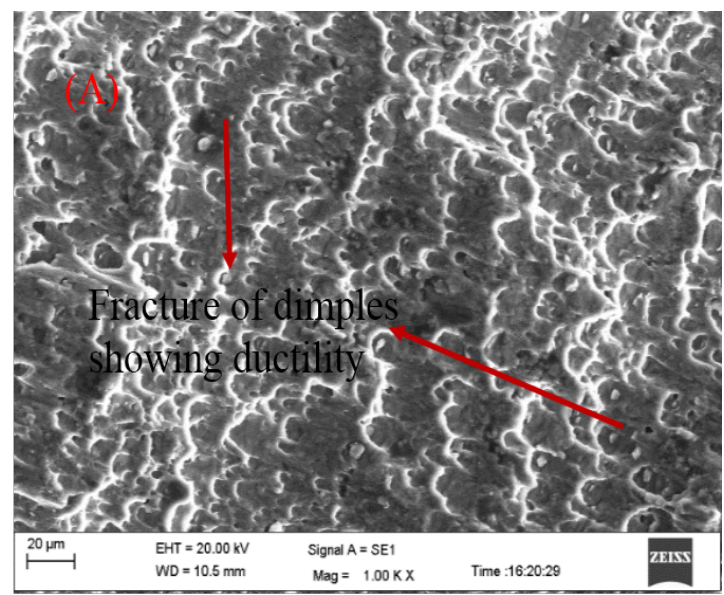

(b)

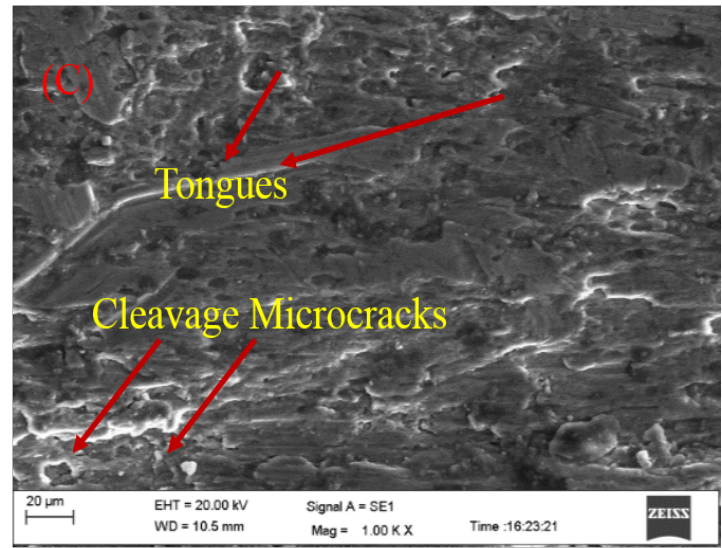

(d)

Figure 8. SEM pictures of fracture surfaces in upper sheet of FSSW sample No. 7. (a) Fracture surface on upper sheet. (b) Fracture surface morphology (FSM) with high magnification at point A. (c) FSM with high magnification at point B. (d) FSM with high magnification at point $\mathrm{C}$. 


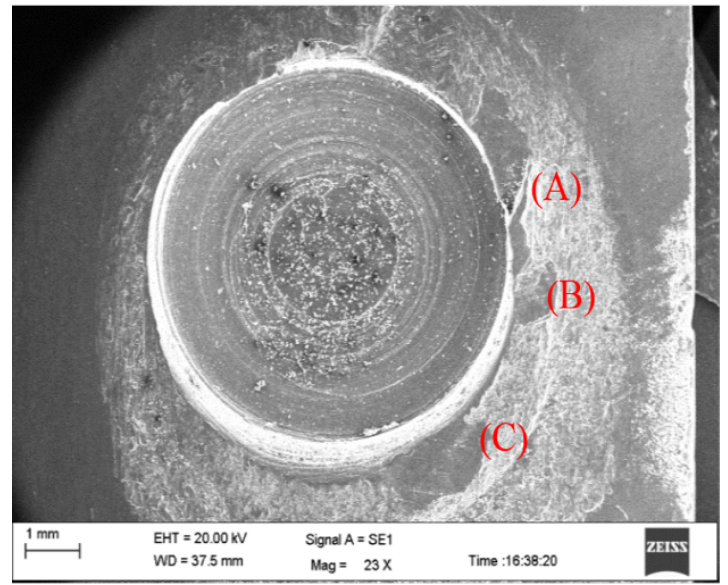

(a)

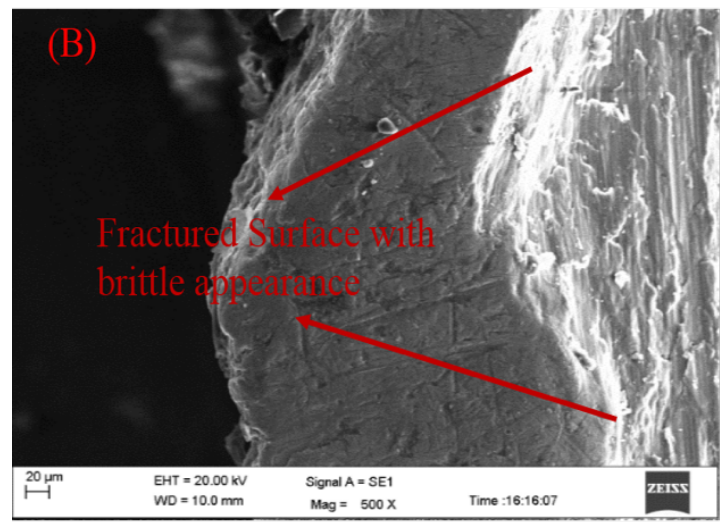

(c)

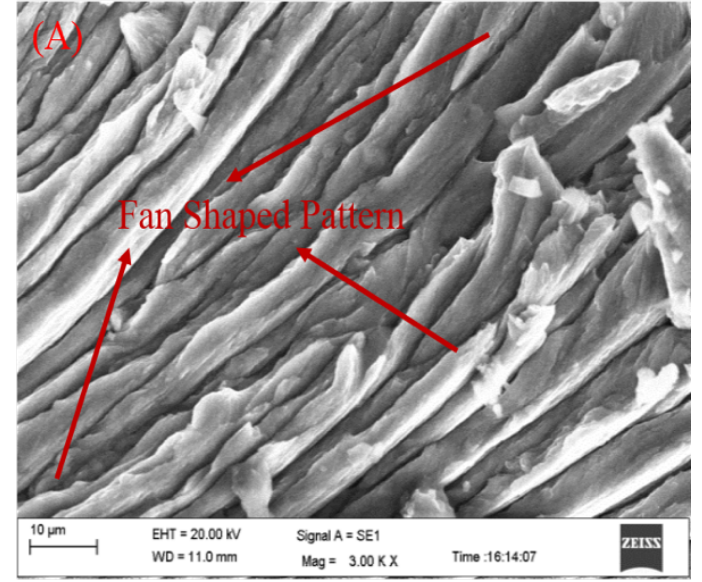

(b)

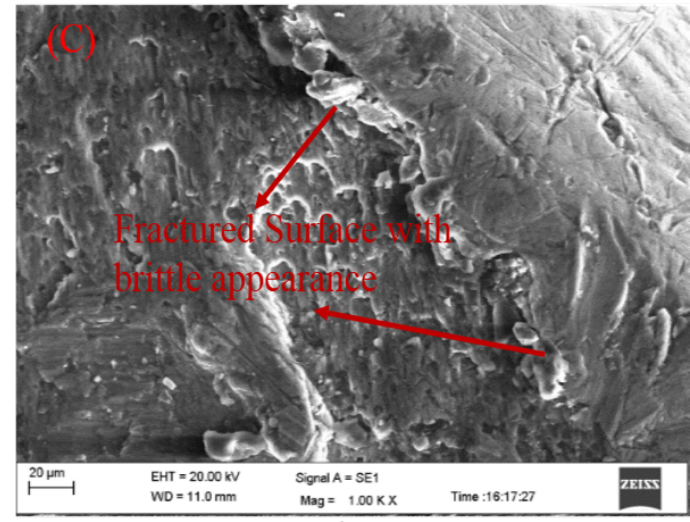

(d)

Figure 9. SEM pictures of fracture surfaces in lower sheet of FSSW sample No. 7: (a) fracture surface on lower sheet; (b) FSM with high magnification at point A; (c) FSM with high magnification at point B; (d) FSM with high magnification at point $\mathrm{C}$.

SEM fractographs of surfaces in upper and lower sheet (AA 6082-T6) of FSSW sample No. 6 (TRS 1500 rpm, DT 15 Secs and SD $12 \mathrm{~mm}$ ) and images of 3 points A, B, and C with higher magnification are shown in Figures 10 and 11, respectively. Fig. 10 (b) for point A and Fig. 10 (c) for point B show the fracture mechanism, which consists of numerous coarser dimples. This dimple rupture is the indication of fracture that occurred due to ductility. Fig. 10 (d) indicates the crack initiation regions at point C. Fig. 11 (a) illustrates the large-scale vision of the fractured surface. It shows a uniform rough surface. The ductile fractured feature with voids nucleation and coalescence was found in the enlarged view of the fracture surface. Fig. 11 (b) for point A indicates the slope of micro voids (shear dimples) on the two fractured surfaces. Various spherical dimples were found in the fracture mechanism as shown in Fig. 11 (c). These dimples resulting from tensile load represent microvoids. Fig. 11 (d) shows rupture of dimples indicating ductile nature of fracture. SEM fractographs of surfaces in upper and lower sheet (AA 6082-T6) of FSSW sample No. 4 (TRS $1500 \mathrm{rpm}$, DT $5 \mathrm{sec}$ and SD $14 \mathrm{~mm}$ ) and images of 3 points A, $\mathrm{B}$, and $\mathrm{C}$ with higher magnification are shown in Figures 12 and 13, respectively. 


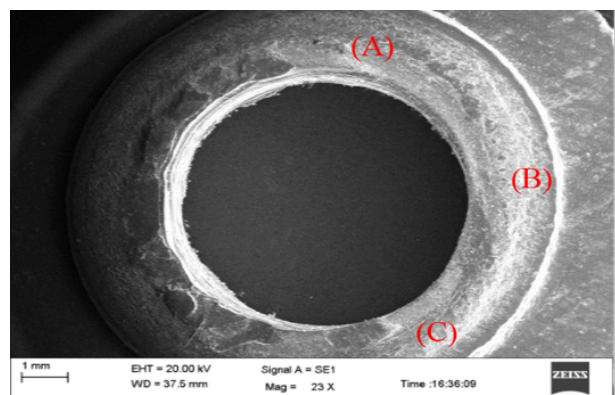

(a)

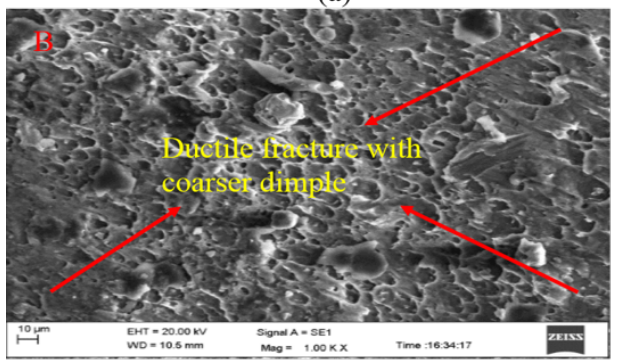

(c)

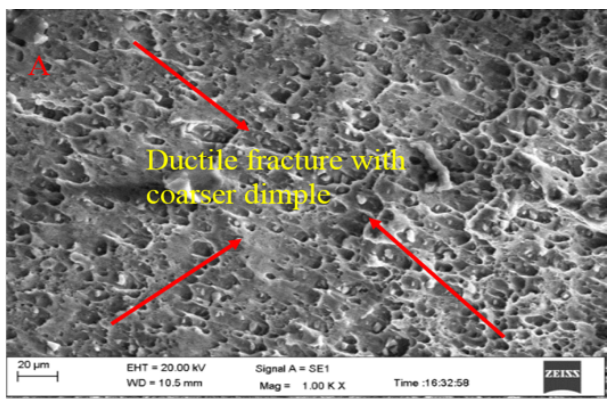

(b)

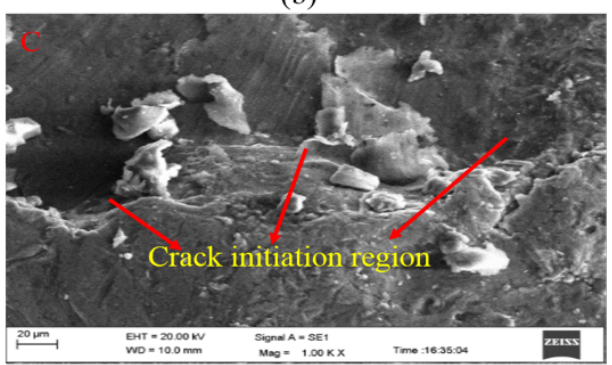

(d)

Figure 10. SEM pictures of fracture surfaces in upper sheet of FSSW sample No. 6: (a) fractures surface on upper sheet; (b) FSM with high magnification at point A; (c) FSM with high magnification at point B; (d) FSM with high magnification at point $\mathrm{C}$.

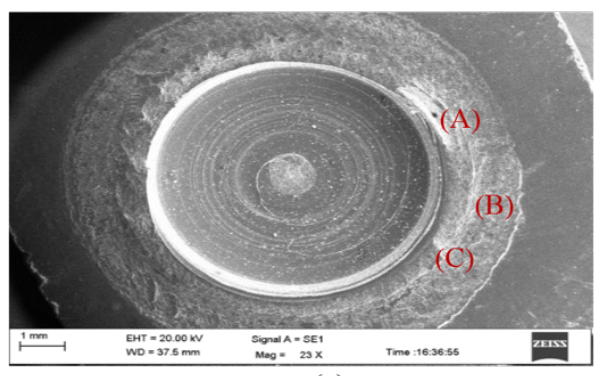

(a)

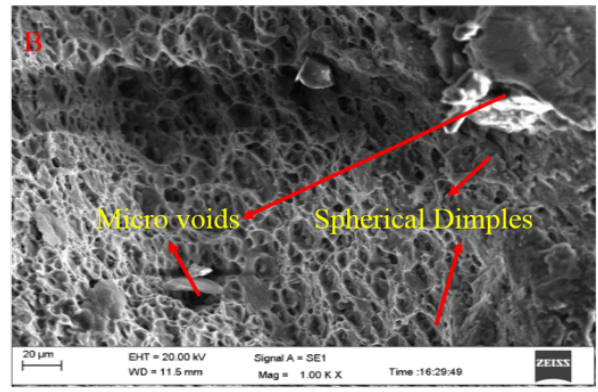

(c)
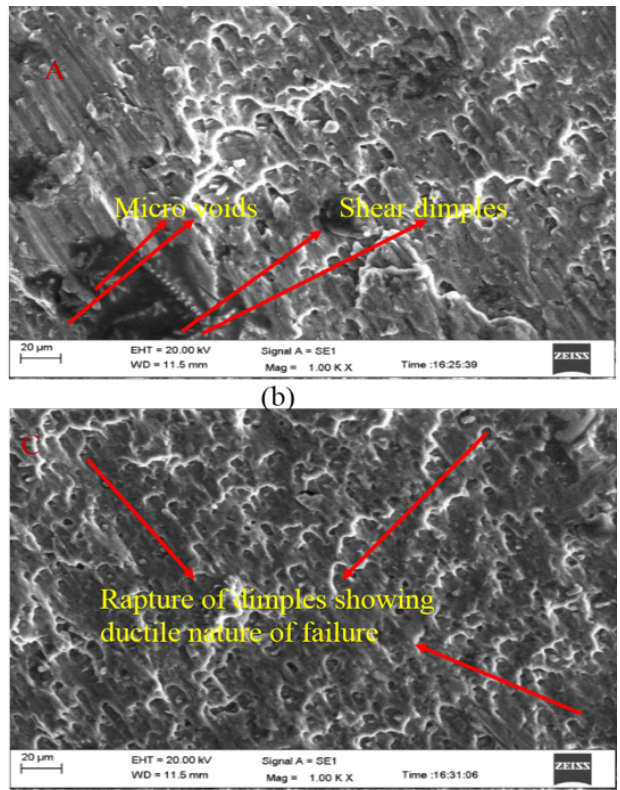

(d)

Figure 11. SEM pictures of fracture surfaces in lower sheet of FSSW sample No. 6: (a) Fractures surface on lower sheet; (b) FSM with high magnification at point A; (c) FSM with high magnification at point B; (d) FSM with high magnification at point $\mathrm{C}$. 
Fig. 12 (b, c, d) shows flat surface along with few ridge like sturctures due to larger forces acting on upper sheet. No dimples are observed at the fractured surface. This was the indication of weaker bonding strength. The transgranular river flow pattern observed in Fig. 12 (b and c) indicates the early stages of crack growth. Fig. 12 (c) for point B shows crack propogation exhibiting mixture of dimples and cleavage fracture. Figure 13 (b) shows crack initiation region at point A. Fig. 13 (c and d) shows cleavage fracture accompanied by microscopic traces of local plastic deformation. A river pattern of radiating lines as shown in Fig. 13 (c and d) indicated brittle nature of fracture. Fig. 13 (c) shows flat facets. Fig. 13 (d) shows tearing edges indicated weaker bonding. The absence of finer dimples had indicated lower bonding strength. Thus, TSFL was found to be lower for this joint.

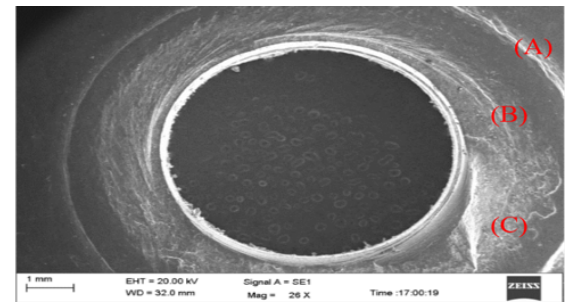

(a)

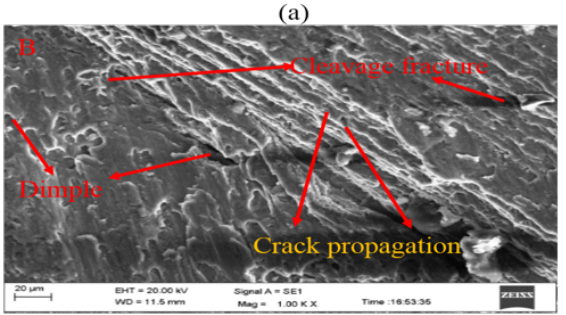

(b)
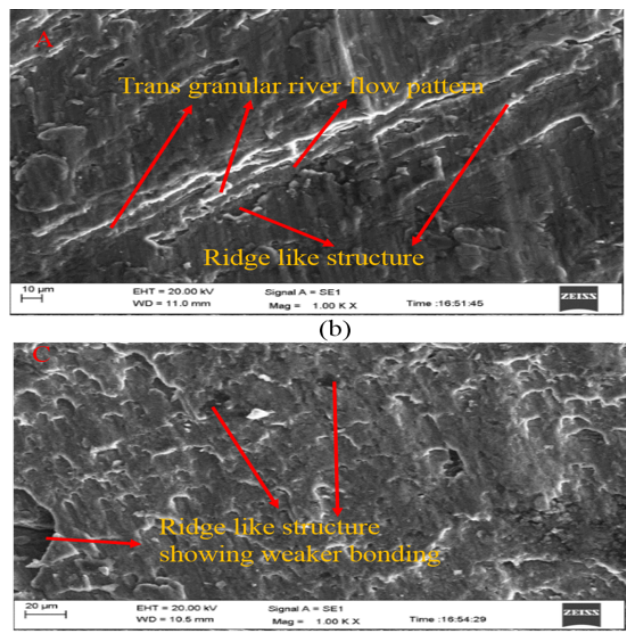

(d)

Figure 12. SEM pictures of fracture surfaces in upper sheet of FSSW Sample No. 4. (a) Fractures surface on upper sheet; (b) FSM with high magnification at point A; (c) FSM morphology with high magnification at point B; (d) FSM with high magnification at point $\mathrm{C}$.

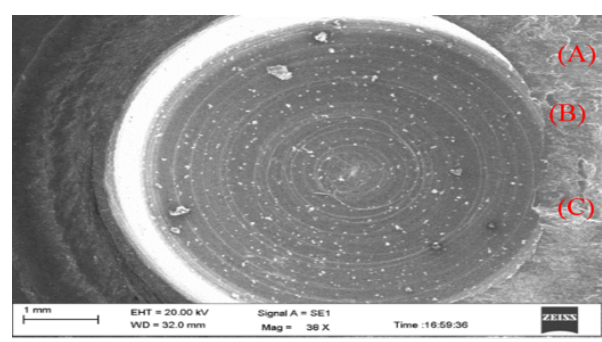

(a)

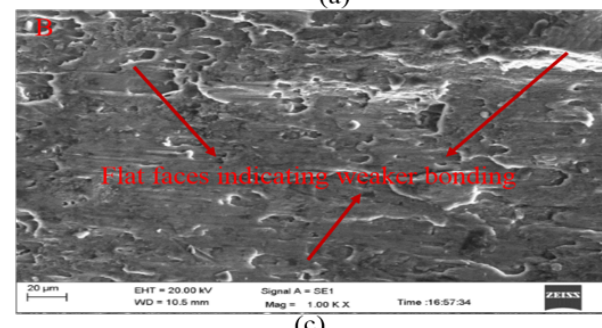

(c)

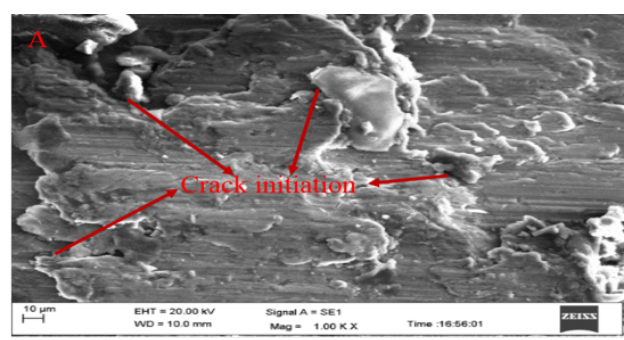

(b)

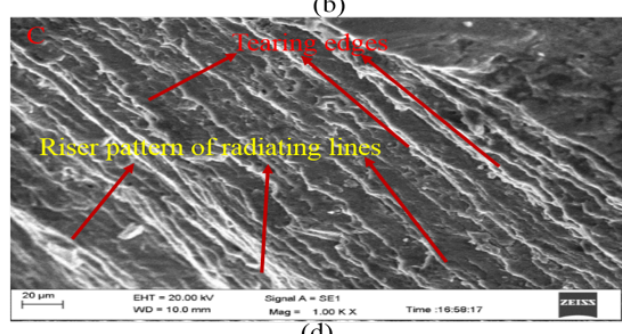

(d)

Figure 13. SEM pictures of fracture surfaces in lower sheet of FSSW sample No. 4. (a) Fractures surface on lower sheet; (b) FSM with high magnification at points A; (c) FSM with high magnification at point B; (d) FSM with high magnification at point $\mathrm{C}$. 


\section{COMPARISON OF FINDINGS WITH PRESENT INVESTIGATION AND REPORTED WORK}

The shear force of friction stir spot welded AA 6082 joint was found to be $3.2 \mathrm{KN}$. Friction stir spot welded joint obtained through the optimized process parameters through had increased the shear strength of welded joint. Through the previously performed experiment, it can be concluded that the optimum process parameters had improved the welding quality of the weld along with the shear strength. Table 11 shows the comparison on shear force through the present investigation and previous results obtained from various researchers working in the area of FSSW.

Table 10. Comparison of published results through present investigation.

\begin{tabular}{|c|c|c|c|c|}
\hline S. No & Authors' & Alloy & $\begin{array}{c}\text { Process } \\
\text { Parameters }\end{array}$ & Finding \\
\hline 1. & $\begin{array}{l}\text { Ahmed et al. } \\
\qquad(2016)\end{array}$ & Mn TWIP & $\mathrm{TRS}=750 \mathrm{rpm}$ & $\begin{array}{l}\text { Shear strength was } \\
\text { found to be } 3 \mathrm{KN} \text {. }\end{array}$ \\
\hline 2. & $\begin{array}{l}\text { Aydin et al. } \\
\text { (2019) }\end{array}$ & AA1050- AA3105 & & $\begin{array}{l}\text { Shear strength was } \\
\text { improved by } 7 \% \text {. }\end{array}$ \\
\hline 3. & $\begin{array}{l}\text { Bayazid et al. } \\
\text { (2015) }\end{array}$ & AA $6063-7075$ & $\mathrm{TRS}=1600 \mathrm{rpm}$ & $\begin{array}{l}\text { Influence of TRS, TS } \\
\text { and plates position } \\
\text { parameters on strength } \\
\text { was } 59 \%, 30 \% \text { and } 7 \% \text {. }\end{array}$ \\
\hline 4. & $\begin{array}{l}\text { Muhayat et al. } \\
\qquad(2019)\end{array}$ & AA 6082-T6 & $\begin{array}{c}\text { Pin diameter }= \\
3 \mathrm{~mm} \\
\mathrm{DT}=3 \mathrm{sec}\end{array}$ & $\begin{array}{c}\text { Shear strength was } \\
\text { obtained to be } 4.981 \\
\text { KN. }\end{array}$ \\
\hline 5. & Ojo et al. (2018) & Al clad AA 2219 & $\mathrm{TRS}=1500 \mathrm{rpm}$ & $\begin{array}{l}\text { Maximum lap shear } \\
\text { failure loads of } 4.0 \\
\mathrm{KN} \text { in pin less weld. }\end{array}$ \\
\hline 6. & Prasath et al. (2015) & $\mathrm{ZM} 21$ to $\mathrm{AZ} 31$ & $\mathrm{TRS}=2100 \mathrm{rpm}$ & $\begin{array}{c}\text { Axial force was } \\
\text { obtained to } 4 . \mathrm{KN} \text {. }\end{array}$ \\
\hline 7. & $\begin{array}{c}\text { Present } \\
\text { Investigation }\end{array}$ & AA 6062-T6 & $\begin{array}{c}\text { TRS }=2000 \mathrm{rpm} \\
\mathrm{DT}=15 \mathrm{sec} \\
\mathrm{SD}=16 \mathrm{~mm}\end{array}$ & $\begin{array}{l}\text { Shear strength was } \\
\text { found to be } 3.2 \mathrm{KN} \text {. }\end{array}$ \\
\hline
\end{tabular}




\section{CONCLUSION}

In the present investigation, FSSW was used to weld AA 6082-T6 aluminum alloy. The influence of TRS, DT, and SD on lap joint surfaces, microstructure, and lap shear properties of the FSSW joints was mainly investigated. FSSW of AA 6082 T6 was successfully done through vertical milling machine. TRS was the most significant parameter, followed by DT. From Taguchi analysis, the optimum parameters for TSFL are at TRS of $2000 \mathrm{rpm}$, DT of $15 \mathrm{sec}$, and SD of $16 \mathrm{~mm}$.

A comparison between forecasted values by Taguchi method with the results found through confirmation tests revealed an excellent agreement, validating the optimum design settings. The increase in TRS leads to an increase in the bond width and coarsening of grains in SZ, which provides higher strength. Fracture morphologies from SEM analysis indicated partly ductile and partly brittle nature of fractures at various fractured surfaces.

From SEM analysis of sample 7, the differences in grain size were evident at SZ, TMAZ, HAZ, and BMZ. Microstucture examination witnessed dynamically recrystallized structure developed in the SZ. Compressive residual stresses at $\mathrm{SZ}$ are found to be lesser than those at TMAZ region.

Elongated grains due to insufficient temperature were observed in TMAZ. Partial bonding can be noticed in $\mathrm{HAZ}$, with no changes in grain structure. Grain structure of BMZ remains unaffected during FSSW.

\section{ACKNOWLEDGMENT}

The authors are grateful to the Department of Mechanical Engineering, GNIOT, Greater Noida, AIRF lab, JNU, New Delhi, and Bansal testing Services, Ghaziabad, for providing facilities to carry out the above work. The authors would like to express their thanks to Dr. Ruchika Pal at AIRF, JNU, New Delhi, for providing support during SEM analysis and Fractography analysis.

\section{REFERENCES}

Ahmed M.M.Z., Ahmed E., Hamada A. S., Khodir, S.A., Seleman M.M. El- S., Wynne B.P. 2016.

Microstructure and mechanical properties evolution of friction stir spot welded high-Mn twinning-induced plasticity steel. Materials and Design. 91:378-387.

Aydin H., Tuncel O., Yuce C., Tutar M., Yavuz N., Bayram A. 2014. Effect of Rotational Speed and Dwell Time on Mechanical Properties of Dissimilar AA1050- AA3105 Friction Stir Spot Welded Joints. Materials Testing. 56,10:818-825.

Bayazid S.M., Farhangi H., Ghahramani A. 2015. Investigation of friction stir welding parameters of 60637075 aluminum alloys by Taguchi method. Procedia Mater Sci 11:6-

11. https://doi.org/10.1016/j.mspro.2015.11.007

Bozzi S., Etter A. L., Baudin T., Robineau A., Goussain J. C. 2008. Mechanical behavior and microstructure of aluminum-steel sheets joined by FSSW. Texture, Stress, and Microstructure. Article ID 360617, 1-8.

Cakan A., Ugurlu M., Kaygusuz E. 2019. Effect of weld parameters on the microstructure and mechanical properties of dissimilar friction stir joints between pure copper and the aluminum alloy AA7075-T6. Materials Testing. 61, $2: 142-148$.

Cevik B. 2016. Influence of welding Parameters on the fracture of PE300 polyethylene friction stir spot welds. Materials Testing. 58, 11-12: 959-962. 
Effertz P.S., Infante, V., Quintino L., Suhuddin U., Hanke S., dos Santos J.F. 2016. Fatigue life assessment of friction spot welded 7050-T76 aluminium alloy using Weibull distribution. International Journal of Fatigue. 87, 381-390.

Effertz P.S., Quintino L., Infante V. 2017. The optimization of process parameters for friction spot welded 7050-T76 aluminium alloy using a Taguchi orthogonal array. International Journal of Advanced manufacturing Technology. 91(9-12):3683-3695.

Elfar O. M. R., Rashad R. M., Megahed H. 2016. Process Parameters Optimization for Friction Stir Welding of Pure Aluminium to Brass (CuZn30) using Taguchi Technique. MATEC Web of Conferences, 43, 03005:1-6.

Fentahun M.A., Savaş M.A. 2018. Materials Used in Automotive Manufacture and Material Selection Using Ashby Charts, International Journal of Materials Engineering. 8:3, 40-54.

Fitzpatrick M.E., Fry A.T., Holdway P., Kandil F.A., Shackleton J., Suominen L. 2005. Determination of residual stresses by x-ray diffraction. Measurement Good Practice Guide. 52,2.

Ghassemieh E. 2011. Materials in Automotive Application, State of the Art and Prospects. New Trends and Developments in Automotive Industry. https://doi.org/10.5772/13286

Guler H. 2015. Investigation of the tool effect on the strength of friction stir spot welded aluminum specimens: A comparative study. Materials Testing. 57, $3: 239-244$.

Hirsch J. 2014. Recent development in aluminium for automotive applications. Transactions of Nonferrous Metals Society of China. 24:7, 1995-2002.

Jambhale S., Kumar S., Kumar S. 2020. A Novel Flat Friction Stir Spot Welding of Triple Sheet Dissimilar Aluminium Alloys: Analyzing Mechanical Properties and Residual Stresses at Weld Region. Trans Indian Inst Met 73, 2205-2220.

(2005). Mazda Develops World's First Aluminum Joining Technology Using Friction Heat. Assembly Automation. 25, 4. https://doi.org/10.1108/aa.2005.03325dab.002

Mazzaferro C. C. P., Rosendo T. S., Tier M. A. D., Mazzaferro, J. A. E., Dos Santos J. F., Strohaecker T. R. 2015. Microstructural and Mechanical Observations of Galvanized TRIP Steel after Friction Stir Spot Welding. Materials and Manufacturing Processes. 30:9, 1090-1103.

Montgomery DC, 2009. Design and analysis of experiments. 7th edition. Wiley, New York.

Muhayat N., Putra B.P., Triyono. 2019. Mechanical Properties and Microstructure of Friction Stir Spot Welded 6082-T6 Aluminium Alloy Joint. MATEC Web of Conferences 269, 01005.

Ojo O.O., Tejan E., Kaluc E. 2015. Friction stir spot welding of aluminum alloys. A recent review. Material Testing. 57, 7-8: 609-627.

Ojo O.O., Tejan E., Kaluc E. 2018. Effect of residual Alclad on friction stir spot welds of AA 2219 alloys. Materials Testing. 60,10:979-988.

Prabhuraj P., Rajakumar S., Balasubramanian V., Sridhar K., Lakshminarayanan A.K. (2016). Mechanical and corrosion behaviour of friction. Journal of Manufacturing Engineering.11,4:234-238.

Prasath S., Vijayan S., Rao S. 2016. Optimization of friction stir welding process parameters for joining ZM 21 to AZ 31 of dissimilar magnesium alloys using Taguchi technique. La Metallurgia Italiana. 5, 25-33.

Sameer MD., Birru A. K. 2019. Mechanical and metallurgical properties of friction stir welded dissimilar joints of AZ91 magnesium alloy and AA 6082-T6 aluminium alloy. Journal of Magnesium and Alloys. 7, 264 271. 
Sunnapu C., Kolli M. 2020. Tool shoulder and pin geometry's effect on friction stir welding: A study of literature, Materials today proceeding, Article in Press https://doi.org/10.1016/j.matpr.2020.05.601

Todor M.P., \& Kiss I. 2016. Systematic approach on materials selection in the automotive industry for making vehicles lighter, safer and more fuel-efficient. Applied Engineering Letters. 1:4, 91-97.

Tutar M., Aydin H., Bayram, A. 2017. Multi objective Taguchi optimization approach for resistance spot welding of cold rolled TWIP steel sheets. IOP Conf. Series: Journal of Physics: Conf. Series 885,012010. 